\title{
GIS and Wave Modeling for Establishing a Potential Area of Aquaculture-Case Study: Central Atlantic Part of the Moroccan Coast
}

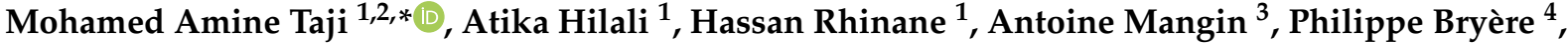 \\ Abdelatif Orbi ${ }^{5}$ (D), Hassan Mabchour ${ }^{6,7}$, Bendahhou Zourarah ${ }^{8}$ and Aïssa Benazzouz ${ }^{6}$ (D)
}

\section{check for}

Citation: Taji, M.A.; Hilali, A.; Rhinane, H.; Mangin, A.; Bryère, P.; Orbi, A.; Mabchour, H.; Zourarah, B.; Benazzouz, A. GIS and Wave Modeling for Establishing a Potential Area of Aquaculture-Case Study: Central Atlantic Part of the Moroccan Coast. Fluids 2022, 7, 67. https:// doi.org/10.3390/fluids7020067

Academic Editor: Giuliano De Stefano

Received: 21 December 2021

Accepted: 21 January 2022

Published: 7 February 2022

Publisher's Note: MDPI stays neutral with regard to jurisdictional claims in published maps and institutional affiliations.

Copyright: (C) 2022 by the authors. Licensee MDPI, Basel, Switzerland. This article is an open access article distributed under the terms and conditions of the Creative Commons Attribution (CC BY) license (https:// creativecommons.org/licenses/by/ $4.0 /)$.
1 Geosciences Laboratory, Faculty of Sciences Ain Chock, University Hassan II, Casablanca 20100, Morocco; hilaliat@yahoo.fr (A.H.); h.rhinane@gmail.com (H.R.)

2 Argans UK, 1 Davy Road, Plymouth Science Park, Derriford, Plymouth PL6 8BX, UK

3 ACRI-ST, 260 Route du pin Montard, 06904 Nice, France; antoine.mangin@acri-st.fr

4 Argans France, Etablissement de Brest, Le Grand Large Quai de la Douane, 29200 Brest, France; pbryere@argans.eu

5 National Institute of Fisheries Research (INRH), Casablanca 20180, Morocco; abdellatiforbi@gmail.com

6 Nautical Science and Naval Engineering Department, Institut Supérieur d'Etudes Maritimes, Km 7, Road El Jadida, Casablanca 20520, Morocco; hassan.mabchour@gmail.com (H.M.); benazzouz.metlisem@gmail.com (A.B.)

7 Laboratory Mechanical Control and Characterization of Materials and Structures, Department of Mechanics, ENSEM, Casablanca 20232, Morocco

8 Marine Geosciences and Sol Sciences Laboratory, Associated Unit URAC 45, Department of Geology, Faculty of Sciences, University Chouaib Doukkali, El Jadida 24000, Morocco; zourarah@gmail.com

* Correspondence: taji.mohamedamine@gmail.com; Tel.: +212-660-57-76-31

Abstract: Marine aquaculture has proliferated over the past decade, expanding into new, untapped open-water cultivation areas, such as lakes, rivers and deeper offshore environments, in response to increasing demand for seafood by consumers. However, to ensure sustainable development, it is necessary to minimize the impact of other ocean activities and the environment through science-based spatial planning. The choice of the primary site (physical carrying capacity) depends mainly on the aquaculture system, which varies around the world. However, the site is considered one of the factors (production, ecological and social) keys to any aquaculture operation, especially in the African continent. This choice affects both the success and sustainability of the products cultivated and the resolution of conflicts between different activities as well as the rational use of space. This study aims to identify suitable areas (primary site selection) for aquaculture in the Moroccan Atlantic continental shelf focused on the sub-area located between Cap Ghir $31.25^{\circ}$ and Tarfaya $27.47^{\circ}$, based on the assessment of the dominant wave energy by implementing the hydrodynamical SWAN (Simulating Waves Nearshore) model dedicated for this kind of study. We derived the inputs for the SWAN model from WW3 (WAVEWATCH III model), which the AVISO data-products have extensively validated. The results show that, even if the Atlantic area is known for the agitation of its seas, there is the possibility of having adequate areas for aquaculture with an overall capacity that could extinguish the 389 ha in the study area if aquatic cultivation manages to exploit the offshore areas. At the level of the sub-zone belonging to the sous-Massa region (zone 1), the results show a strong coherence between the values of the surfaces estimated by the study and the actual values resulting from the development plan, with a value of $69 \mathrm{Ha}$ for the first and 75 for the second, i.e., equal to $6 \mathrm{Ha}$, due to the geomorphology of the coast and natural coastal shelters, which play favorably on the environment for aquaculture development. These areas may attract the greed of investors, although they are in the process of being the subject of an aquaculture development plan.

Keywords: wave model; SWAN; aquaculture; primary site selection; environmental impact; carrying capacity; GIS 


\section{Introduction}

In Morocco, the aquaculture sector produced from 433 tonnes of output in 2013 [1] to 900 tonnes in 2019, which remains below its potential. According to the National Aquaculture Development Agency (ANDA), marine aquaculture in Morocco holds much promise. The country's natural aquaculture potential could be as high as 380,000 tonnes per year [2].

The Kingdom of Morocco, since 2009, has refined its fisheries strategy, called the Halieutis plan, to better meet the challenges by 2020 in improving aquaculture performance, enhancing food security, maintaining the long-term sustainability of aquatic resources and ensuring supply security and environmental protection. However, the authorities set out goals for a second phase, which will run from 2020 to 2030, to support the national aquaculture development strategy [2]. Considerable efforts should be made by all stakeholders and socio-economic partners in the aquaculture sector to determine potential areas for an aquaculture project.

The aquaculture marine cage requires excellent precision in site selection, unlike a landbased installation. A poor localization can lead to the loss of stock of the species (ex: fish) in the breeze of the cages [3]. Other factors can negatively impact marine aquaculture, such as poor spatial planning [4] or inadequate management procedures [5]. Choosing a site for any fish farm (aquaculture) is crucial because it influences the economic viability through the aquaculture facility's operating costs, production, mortality and overall profitability.

Sustainability issues require particular consideration in the early stages of planning $[6,7]$. According to [8], Sustainable Aquaculture is "where ecological and economic viability persists indefinitely". Namely, it is a complicated process involving the optimal parameters for aquaculture in terms of the carrying capacity and the needs of other users and activities of the resource [9]. In addition, sustainability should not overlook potential impacts and interactions with the environment and the ecosystem.

Following the improved capacity and performance of the Geographic Information System (GIS), it has become an essential tool for decision makers [10] due to the enormous potential of storage, analytics and communication that it offers. Thus, it allows a decision maker to be positioned quickly with the spatial constraints of the environment and to access historical events through spatial remote sensing, which has also become a source of information for GIS.

This ability to integrate and interpret the different parameters or layers of information helps immensely in the detection of potential sites [11], except that the interaction with a large flow of data is not always easy for a decision maker, especially in the absence of a Geo-processing tool [12]. Hence, the interest of the developments carried out under the Python programming language aims to automate the various GIS processes whose analysis scheme is clearly described in this study.

This article aims to give the first selection based on the physical parameters (physical load capacity) of the marine environment [13], which remains an initial identification consisting of the area's suitability.

The selection process will be based mainly on the interpretation of the numerical data of the dominant monthly wave activity during the 14 years (2003-2017) resulting from the SWAN model under the GIS system. We performed the methodology for the central area of Morocco between Cap Ghir $\left(32^{\circ}\right)$ and Tarfaya $\left(28^{\circ}\right)$. As a result of this work, we will:

(i) demonstrate how the SWAN model can give us a broad outline of the feasibility of an aquaculture facility and

(ii) compare the results with the proposed future development plan.

\section{Material and Method}

\subsection{Study Area}

The Moroccan Kingdom is located in the northwest of Africa and has a long coast (about $3500 \mathrm{~km}$ ) [1] with two seafronts, while the Mediterranean (about $500 \mathrm{~km}$ ) surrounds it to the north with the Atlantic (about $3000 \mathrm{~km}$ ) to the west. The neighboring countries are 
Algeria to the east and Mauritania to the south. The country is considered the bridge that links Africa with Europe $(14 \mathrm{~km})$ through the Gibraltar Straits, the only maritime passage between the Atlantic Ocean and the Mediterranean Sea.

Thanks to its sizeable latitudinal extension due to the critical Atlantic shore and an extended continental shelf, this coast is exposed to several low-pressure generating waves and storms, mostly coming from the North Atlantic and hitting the coast's long and creating strong waves along with the coastal band. Morocco's consistent swell and wave energy are recorded during the winter months, usually from December to February [14]. Severe swell episodes are not uncommon. To do this, we need to know the sheltered areas and least exposed to risks. Our study area was initially chosen based on the geometric structure of the continental shelf, which has a particular concavity and, potentially, could house and protect aquaculture farms.

According to this coastal geomorphological aspect, the area that belongs to Morocco's central Atlantic part is selected, bounded by Cape Ghir in the north $\left(31.25^{\circ} \mathrm{N}\right)$ and the town of Tarfaya in the south $\left(27.47^{\circ} \mathrm{N}\right)$ with a coastline extending for approximately $739 \mathrm{~km}$ (Figure 1). In terms of production, the site chosen is one with very high potential [7] and suitable for aquaculture activity [15]. In addition, it could arouse the interest of decision makers in an aquaculture development plans. However, neglecting the aggressiveness of the environment could be fatal for the success and sustainability of any project.

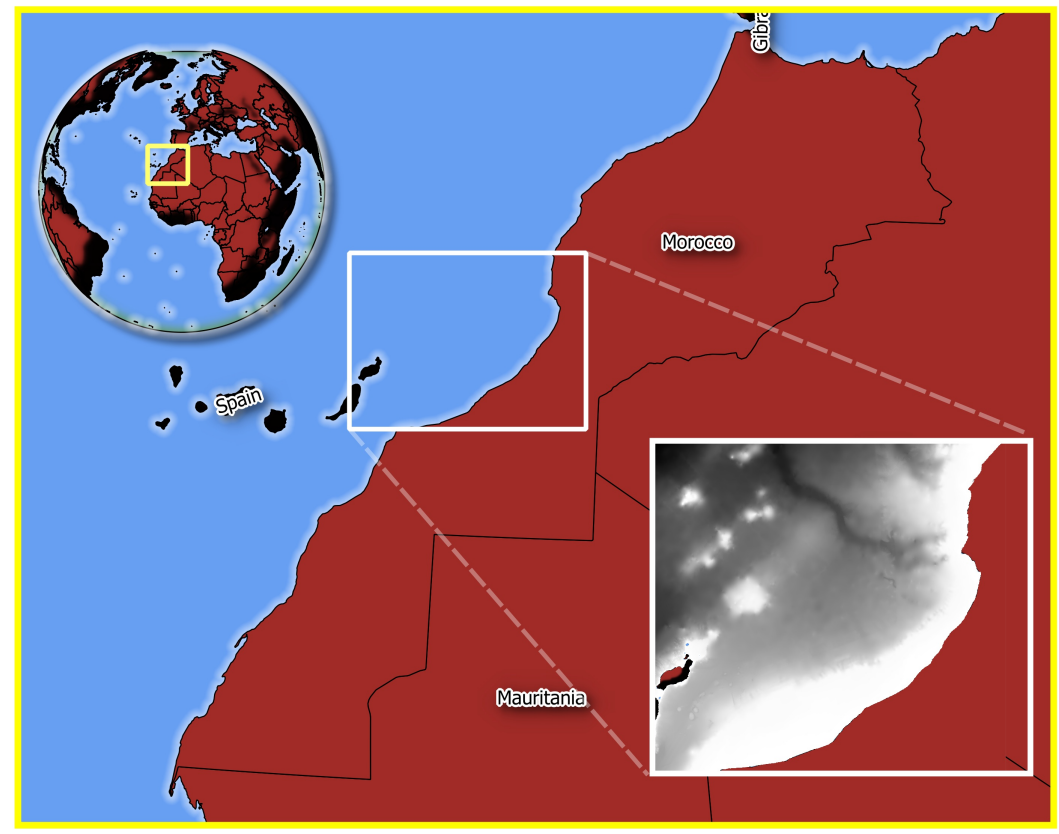

Figure 1. Map showing the Moroccan geographic area. The white shows the central Moroccan studied area. The zoomed section highlights the topographic features derived from the GEBCO database.

\subsection{Data Description}

We used several data sources for this study to locate the primary sites according to the wave energy outputs of the SWAN model. The GEBCO field used for the offshore hydrodynamic forcing conditions provides the data for the bathymetric contour map.

\subsubsection{Bathymetry Data}

As part of the collection of ocean and local scale seafloor terrain model data, bathymetry from GEBCO (General Bathymetric Chart of the Oceans) was used to estimate the water depths of the continental margin. GEBCO is an international reference of the global depth of the ocean floor. It is produced under the joint auspices of International Hydrographic Organization (IHO) and the Intergovernmental Oceanographic Commission (IOC) of UNESCO. 
These data represent the first meshed bathymetric data in the world. They contain information resulting from the assimilation of several heterogeneous data types [16] assuming they all refer to the mean sea level. The first version of this terrain model was published in 2003. The version GeoTIFF 2019 bathymetry was used due to its precision of 15 arc seconds ( $\approx 400 \mathrm{~m}$ at our latitude) (Figure $2 \mathrm{a}$ ) to characterize the underwater relief of the study area.

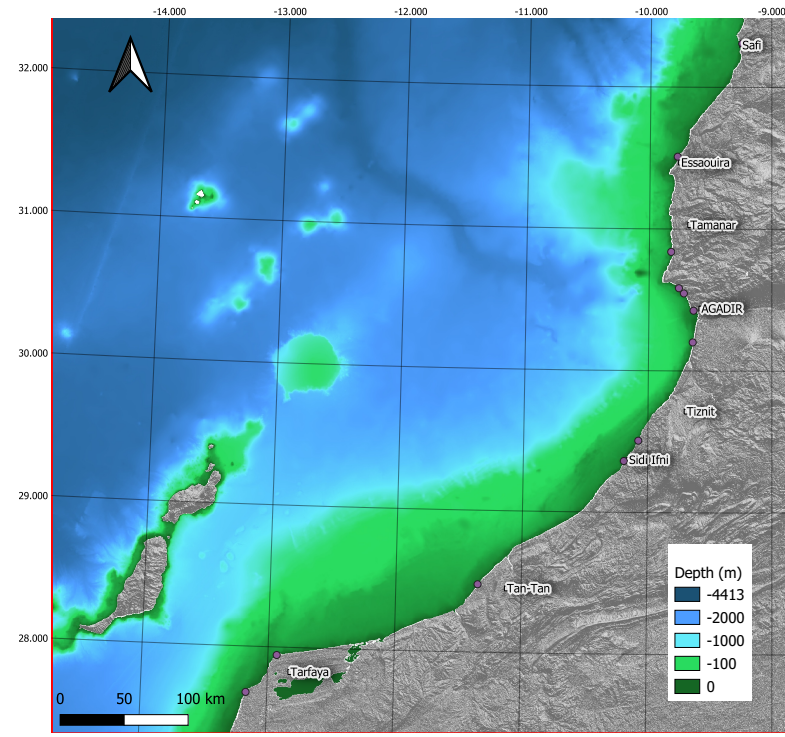

(a)

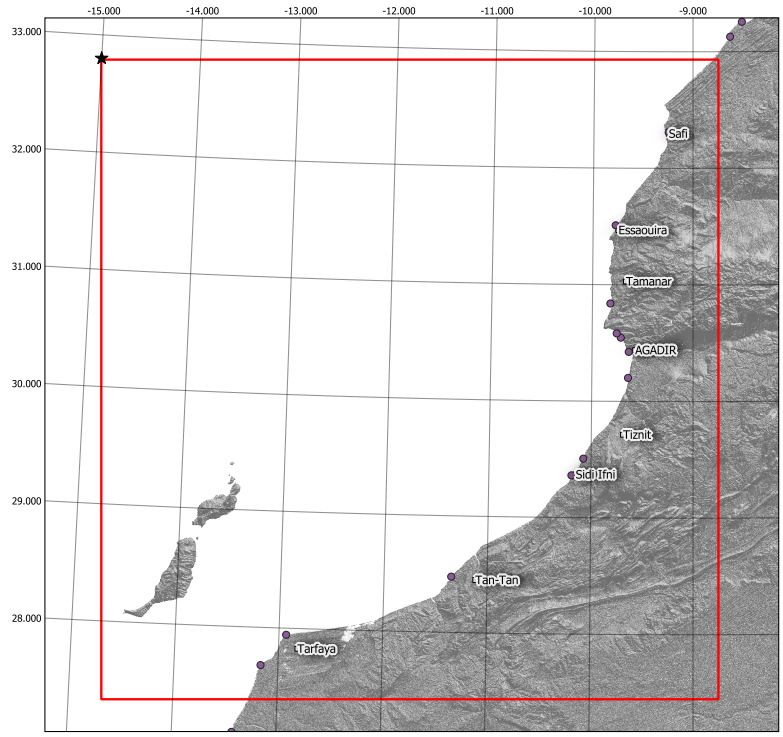

(b)

Figure 2. SWAN model input parameters, (a) Bathymetry of the study area derived from the GEBCO database. (b) Boundary conditions for the central Moroccan zone; the point presents the point of extraction of the parameters.

Shallow waters extend the continental shelf by approximately 12 nautical miles, while the average width of the continental shelf is approximately 40 to $50 \mathrm{~km}$ [17]. The shelf break is at a depth of $200 \mathrm{~m}$, which gives this area the potential to house all the devices of aquaculture farms.

\subsubsection{Boundary Conditions}

The offshore conditions are the first information retrieved at the forcing point (Figure $2 b$ ) of the WW3 model, which is part of the third generation hydrodynamic model as developed at the MMAB of the CEM (the Environmental Modelling Center) of the NCEP (National Environmental Prediction Centers ) to launch the necessary simulations.

Our study used the WW3 model for wave modeling, a third-generation full spectral wave model that solves the wave action density equation. Three types of information were used (Significant wave height, direction and swell period) over fourteen years starting in 2003, with a recording frequency of more than six hours accessible via this FTP link: https: //usgodae.org/pub/outgoing/fnmoc/models/ww3/ (accessed on 15 December 2021).

\subsubsection{AVISO Data}

Satellite altimeter data can provide insights into relevant wave height measurements [18], which have also been extensively used to validate wave modeling $[19,20]$. In our study, we collected the AVISO records https: / /www.aviso.altimetry.fr/en/data/products / (accessed on 15 December 2021) to assess the reliability of the WW3 data used to force our model in the boundary conditions. The AVISO has two satellite altimetry products for ocean waves, along-track and gridded data. We used the gridded data to validate the wave simulation and assimilation $\left(1^{\circ} \times 1^{\circ}\right.$ resolution with 1 -day time intervals). During wave 
simulation, the Hs (significant wave height) was used as an essential observational variable for data assimilation, which was provided from the integration of multiple satellites.

\section{Methodology}

The first general characteristic of the area is its exposure; this refers to the amount of wind and waves it is exposed to. A site exposed to high energy will involve higher initial investments in cages, higher maintenance costs and greater risk, thereby, resulting in higher production costs. However, it will have better hydrodynamics, a reduced environmental impact, better fish welfare and better product quality. On the other hand, a sheltered and protected site will be less exposed to waves and currents, thus, reducing maintenance and costs. Higher risks of significant environmental impacts are often associated with increased coastlines. The methodology is a translation of the temptation to have a clear description of the state of exposure of the area in point of view energy. Two main steps were adopted:

1. Modeling via the SWAN model to obtain continuous information on the propagation of swells on the coast and, more precisely, the site exposure, since the swell's significant height directly relates to breaking the cages [21] .

2. GIS model: the geoprocessing tools maintained by the Python development language under the ANACONDA environment. We studied the propagation results to extract the appropriate places.

The pre-processing of the information used as model input data is crucial for the accuracy of results, whether for the bathymetry or the forcing data. For the first element (bathymetry), the transition to the metric unit is essential for the success of the modeling, materialized by the conversion of the coordinate system (wgs84) to the projected system (UTM zone). For the second dataset (forcing data-from the WW3 model), we proceeded with the validation by correlation analysis to remove any calculation anomaly. We used a second source of information from altimetry data known under the name AVISO satellite developed under the responsibility of CNES from 1992 under the SALP project.

\subsection{Model Description (SWAN)}

Currently, sea state models used for ocean and coastal engineering applications are considered third-generation (3G) because they do not require any assumptions on the initial shape of the spectrum variance. The initial precursor of the $3 \mathrm{G}$ models is the WAM (Wave Model) code (WAMDI Group, 1988); since other models have been developed. Among the most used models, let us mention TOMAWAC [22], WaveWatch III [23,24] and SWAN [25], continuously in development.

Furthermore, Christakos et al. [26] demonstrated that the third-generation high spatial resolution $(250 \mathrm{~m}$ ) SWAN (Simulating Waves Nearshore) digital wave model simulates coastal wave condition swells. Developed at the Delft University of Technology, this model can predict swell conditions using boundary conditions, bathymetric data, wind and current fields. A detailed theoretical and numerical description of the SWAN model was presented in $[25,27]$.

In SWAN, the evolution of the wave action density spectrum (Equation (1)) (equal to the energy density by the relative frequency) is described by an equation of the spectral action balance expressed in Cartesian coordinates through [25] (Equation (1))

$$
\frac{\partial}{\partial t} N+\frac{\partial}{\partial x} c_{x} N+\frac{\partial}{\partial y} c_{y} N \frac{\partial}{\partial \sigma} c_{\sigma} N+\frac{\partial}{\partial \theta} c_{\theta} N=\frac{S}{\sigma}
$$

where $x, y$ are horizontal Cartesian coordinates; $t$ is time, $\theta$ is the propagation direction of each wave component; $c_{x}, c_{y}, c_{\sigma}$ and $c_{\theta}$ stand for the propagation velocity in $x$-space, $y$-space, $\sigma$-space and $\theta$-space, respectively. $S$ is the source term for energy density, including the effects of generation, dissipation and nonlinear wave-wave interaction. The first term on the left-hand side of (Equation (1)) is the rate of change of action density in time, and the second and third terms are the propagation of action in physical space. The fourth and 
fifth terms show the shift in relative frequency and refraction due to bathymetric variations and currents.

\subsection{Set-Up of the SWAN Wave Model (Boundaries and Initial Conditions)}

In order to model waves inside the study area, the first step was to provide proper boundary conditions (wave spectrum characteristics) on the western and northern sides of the domain. To that purpose, we used a 14-year time series with steps of $6 \mathrm{~h}$ and extracted from the WW3 model close to the offshore boundary of our computation grid. Using "R statistic", we estimated twelve-monthly scenarios to describe the dominant situation (in terms of the significant wave height, peak wave direction and peak period of the wave spectrum). The calculation of the 90th percentile via the statistical module after the validation via AVISO altimetry data made this possible. Details of the simulations are in (Table 1).

Table 1. Monthly SWAN model forcing scenarios.

\begin{tabular}{cccc}
\hline Month & Hs & Per & Dir \\
\hline 1 & 3.72 & 347 & 14.578 \\
2 & 3.979 & 346 & 15.073 \\
3 & 3.639 & 349 & 13.869 \\
4 & 3.254 & 349 & 13.277 \\
5 & 2.769 & 353 & 12.077 \\
6 & 2.36 & 353 & 10.726 \\
7 & 2.306 & 352 & 10.732 \\
8 & 2.25 & 350 & 10.803 \\
9 & 2.37 & 351 & 11.881 \\
10 & 3.18 & 347 & 13.102 \\
11 & 3.856 & 349 & 13.978 \\
12 & 3.883 & 342 & 14.479 \\
\hline
\end{tabular}

The SWAN model was implemented on a regular grid $(644 \times 644$ cells $)$ with a spatial resolution equal to $719 \mathrm{~m}$. We considered a JONSWAP spectum for waves distribution, and we choose the "stationary mode" to reduce the model computation time, which took 48 min for the twelve scenarios computations. The model thus provided one output per scenario of Hs for the whole computation domain. On the technical level, the bathymetry information, boundary conditions (Table 1), specification of the modeling criteria and types of output variables (Table 2) are specified in the SWAN command file.

Table 2. SWAN model configuration parameters.

\begin{tabular}{ccc}
\hline & Description & Detail \\
\hline Bathy & Source & Gebco \\
& Resolution & $719 \mathrm{~m} / 719 \mathrm{~m}$ \\
& Number Row /col & $644 / 644$ \\
SWAN parameter & Projection & UTM Zone 28 \\
& COORDinates & Cartesian \\
& Mode stationary & Two dimensional \\
Offshores conditions & Boundspec & Nord and South \\
& Wave watch III & Hs/Dir/Tp \\
\hline
\end{tabular}

\subsection{GIS Modelling}

Identifying sustainable aquaculture sites is a challenge that requires perfect control and knowledge of the parameters impacting the marine environment [28]. For more than thirty years, the integration of decision-support tools, such as the geographic information system (GIS), has been in great demand by decision makers [29], given the efficiency and effectiveness of these tools to respond to the complex spatial problem due to the ability to 
manipulate and combine a multitude of knowledge, information and data [30] to guarantee adequate decision making.

In this study, all geoprocessing processes (Figure 3) were based mainly on the GDAL package released under an X/MIT style Open Source license by the Open Source Geospatial Foundation. We used the python programming language under the ANACONDA environment to automate the the variety of types and spatial resolution of the data used. Multicriteria analysis requires each data's co-registration in the same spatial reference with a comparable resolution and unit. All the data were reclassified or converted for this and following the scheme (Figure 3). For example, bathymetry was reclassified directly without additional geoprocessing, unlike the parameters $(\mathrm{Hs})$ resulting from the modeling and the coastline, which required several other processes.

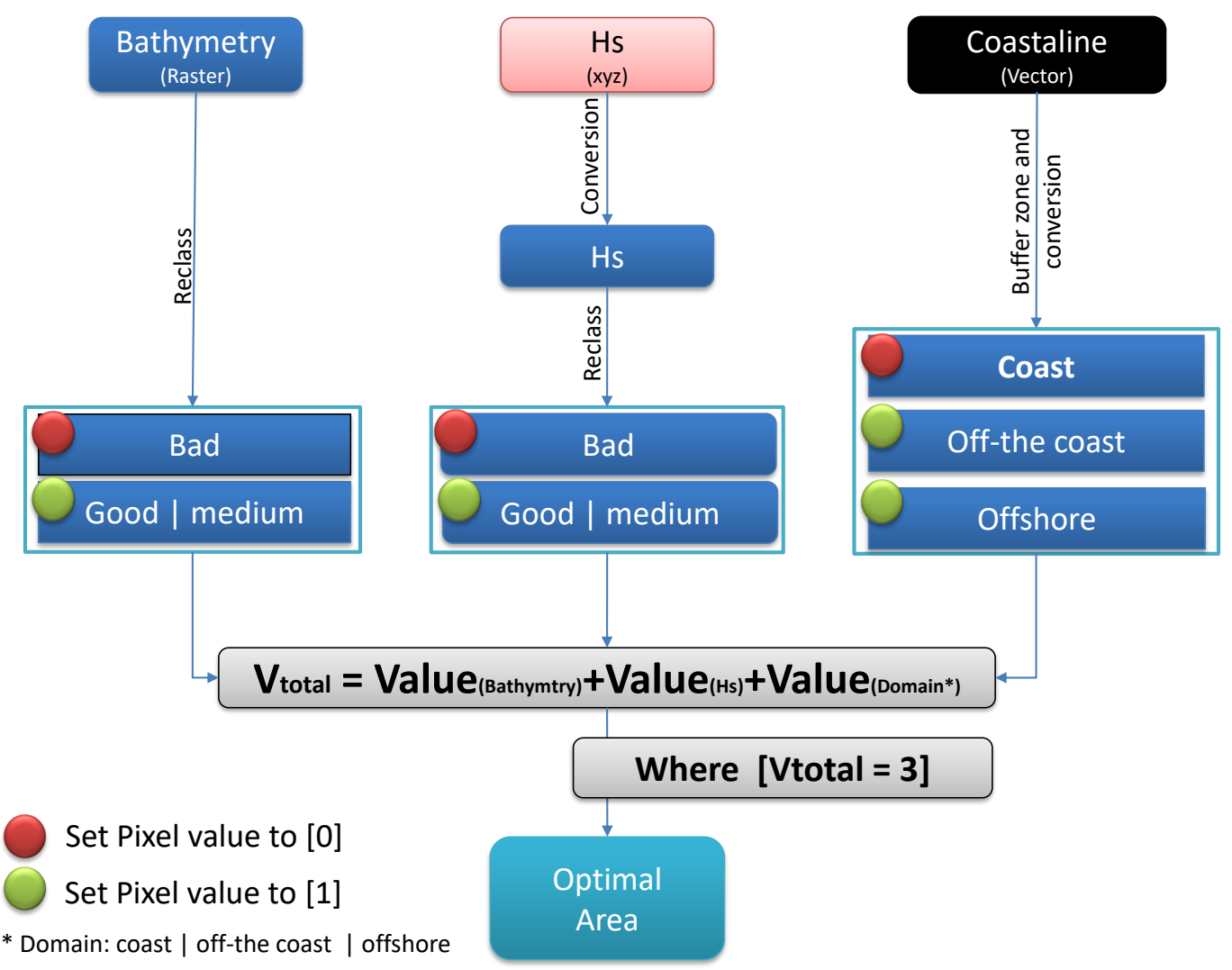

Figure 3. Scheme of the spatial multicriteria analysis applied to the central Atlantic part of Morocco for primary site-selection using GIS processes.

- Coastline: this information was retrieved in vector line format to delimit the coastal zone's different areas, off-the coast and offshore [31,32], via the 'buffer zone' geoprocessing method. The table (Table 3) specifies each area's different characteristics based on the distance from the coastline.

- $\quad$ Significant wave height (Hs): the results obtained from a SWAN model in (XYZ) format require a conversion to Raster while inheriting the bathymetry criteria (Table 2). Following the work of [33,34], a qualitative classification (Table 4) is proposed, which defines the limit of this parameter. 
Table 3. Characterization of coastal and offshore domains.

\begin{tabular}{cccc}
\hline & \multicolumn{2}{c}{ Coastal Area } & Offshore Area \\
\cline { 2 - 4 } & Coast & Off-the Coast & Offshore \\
\hline Coastal exposition & partial & Sheltred & Non-Sheltred \\
Investisement & Low & Medium & High \\
Distance from coast & $500 \mathrm{~m}$ & $500 \mathrm{~m}-3 \mathrm{~km}$ & $3 \mathrm{~km}$ \\
\hline
\end{tabular}

Table 4. Environmental qualification of marine culture cages according to the bathymetry and swell activity constraints [35].

\begin{tabular}{cccc}
\hline & Good & Medium & Bad \\
\hline Bathy & Between 30 and $50 \mathrm{~m}$ & 15 and 30 & 10 \\
Hs & 1 and 3 & 1 & 3 \\
\hline
\end{tabular}

Other limits, such as the domain level (coastal, off-the coast and offshore) and bathymetry, can also be detected. For the first element, the data layer's resolution (equivalent to $712 \mathrm{~m}$ ) will not describe the variability within the zone $(500 \mathrm{~m})$. For this reason, the coastal zone will not be evaluated. Since mooring systems become very complex to install and manage in deep water [36], bathymetric values in excess of $50 \mathrm{~m}$ were excluded. According to the physical characteristics of the environment, the adequate zone is presented by the pixel, which remains favorable (having the value 1) on the three information layers.

\section{Result and Discussion}

\subsection{Model Validation}

The WW3 model simulates wave characteristics over different points over the ocean domain for 14 years with six-hour time steps. The evaluation of simulated wave characteristics against observations in the ocean domain is complex due to the lack of conventional in situ measurements.

Recent advances in satellite technology allow us to use remotely sensed wave data for wave model validation. This study used satellite data sets to validate the simulation wave parameters. We used statistical methods for the analysis and valuation of WW3 model performance, such as the bias, correlation analysis, Mean Square Error and Root Mean Square Error.

The results illustrated by the scatter plot (Figure 4 ) show that the model generally produced results that significantly $(p$ value $=0.01$ ) compared well with measurements of the significant wave heights derived from satellite data with $\mathrm{R}=89 \%$.

\subsection{Interannual and Seasonal Variability}

In order to provide additional information on the interannual and seasonal variability of the intensity of the swells, we studied the evolution of the wave hovmoller diagram for the entire Moroccan zone from South $\left(21^{\circ} \mathrm{N}\right)$ to North $\left(36^{\circ} \mathrm{N}\right)$ with a focus on the central zone from $27^{\circ} \mathrm{N}$ to $31^{\circ} \mathrm{N}$ marked by the red box in (Figure 5). 


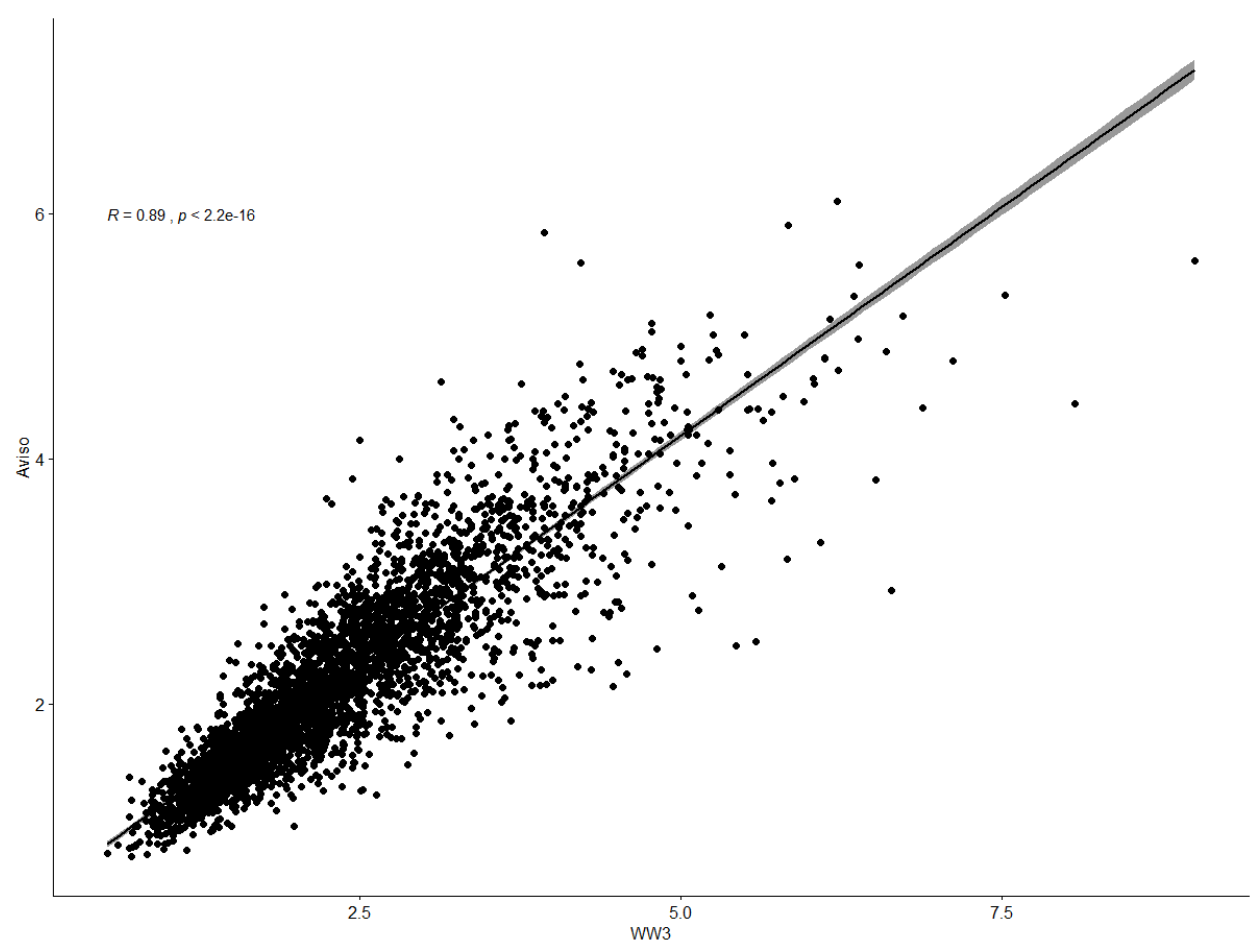

Figure 4. Significant wave height (Hs) comparison from model (WW3) versus co-located altimeter derived AVISO data from 2003 to 2017 given in a scatter plot.

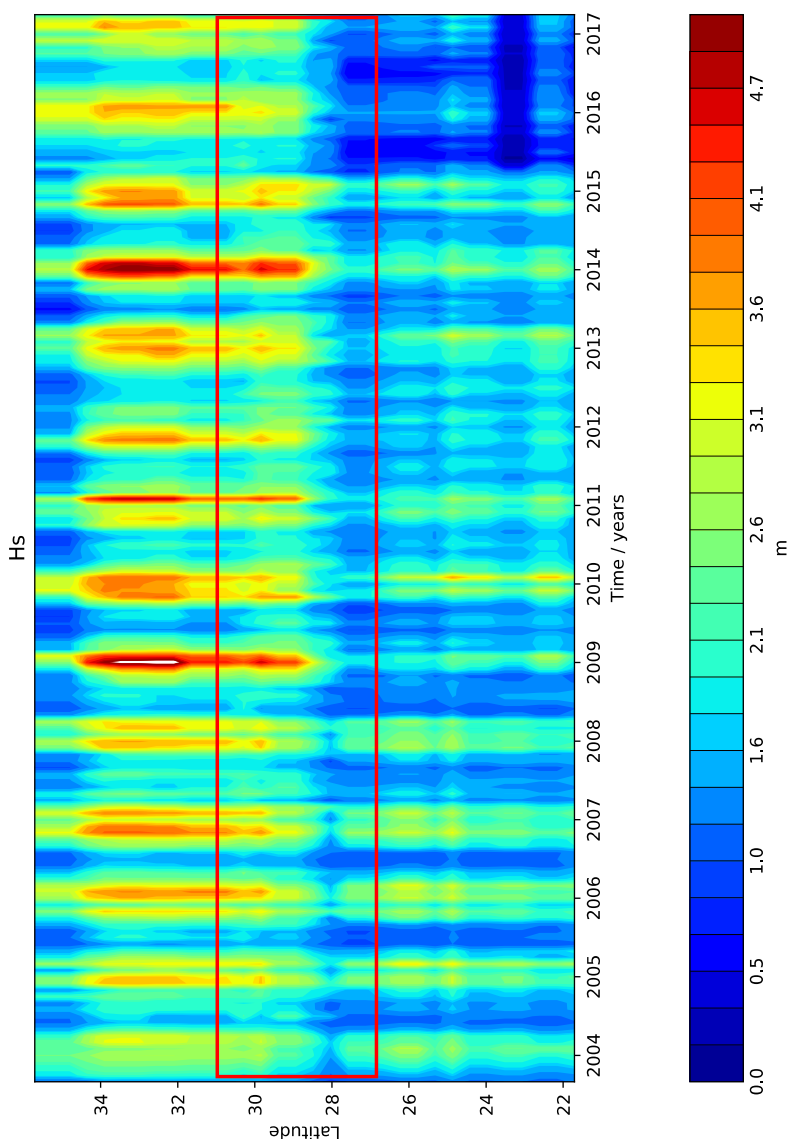

Figure 5. Hovmoller diagrams: Daily 90th percentile of significant wave height (Hs) along the Moroccan coast (2003-2017). 
The spatio-temporal hovmoller diagram exhibits considerable interannual oscillation in the significant wave height intensity covering the 14 years' time series spanning 20042017. Thus, in the whole of the zone, the changes on an annual scale dominate in the variability of the height of the swell showing years with intense activities assimilated to extreme events induced by a higher variability—in the case of 2009, 2011 and 2014 [17], with values exceeding $6 \mathrm{~m}$.

Spatially, the Moroccan area can be broken down into two sub-areas, north of $28^{\circ} \mathrm{N}$, where the swells are mostly more intense with average values between 2.1 and $4 \mathrm{~m}$, and south of $28^{\circ} \mathrm{N}$, characterized by low swell activity with values between 0.5 and $2.9 \mathrm{~m}$. Unlike the southern zone south of $28^{\circ} \mathrm{N}$, the variation is very smooth, with a small magnitude $(1 \mathrm{~m}<\mathrm{Hs}<3.1 \mathrm{~m})$ observed mainly between 2004 and 2008. During the period from 2008 to 2015, the intensity of the swell was at its lowest levels $(<1 \mathrm{~m})$, making this region a sheltered area and protected against intense swells due to the Canary Islands.

\subsection{Monthly Model Product}

To study the seasonal variations of the wave parameter Hs, we used the mean monthly climatological swell intensity, averaged over 14 years of model simulations by the 90th percentile (Figure 6). The mean Hs fields in the study area were substantially different from winter to summer, with the highest values of $\mathrm{Hs}(4 \mathrm{~m})$ observed in the north of the during winter months (December-February), reducing to $1 \mathrm{~m}$ during summer months (June-August). The strength and spatial distribution of variability were broadly consistent throughout the winter months (December-February). These differences lie in the synoptic and regional, seasonal wind-field patterns.

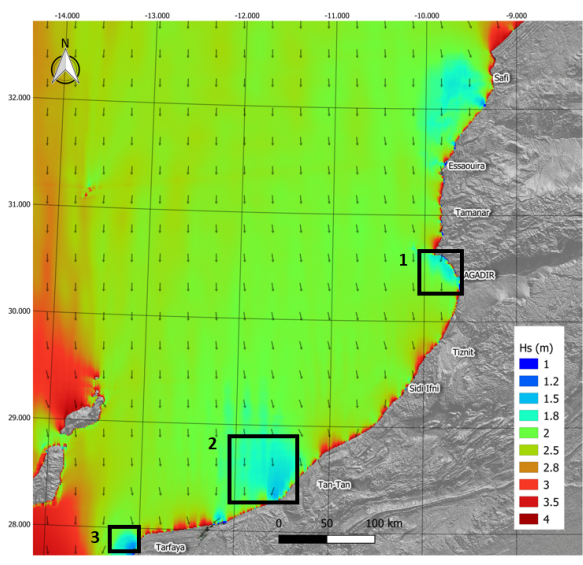

(a)

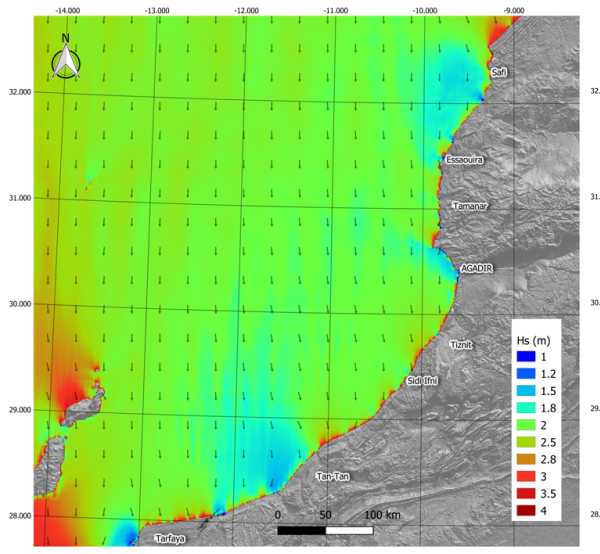

(d)

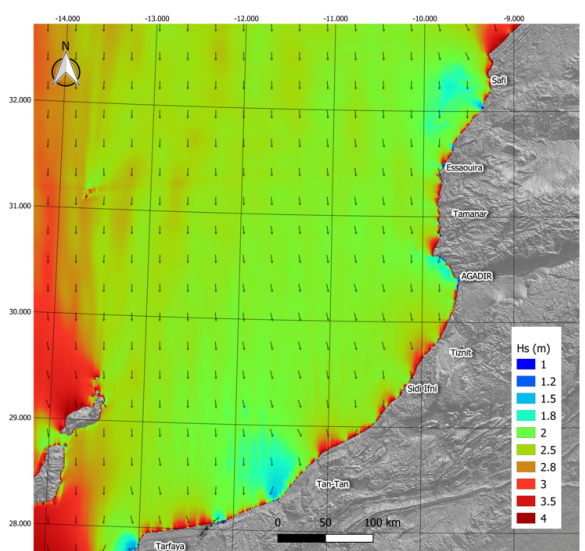

(b)

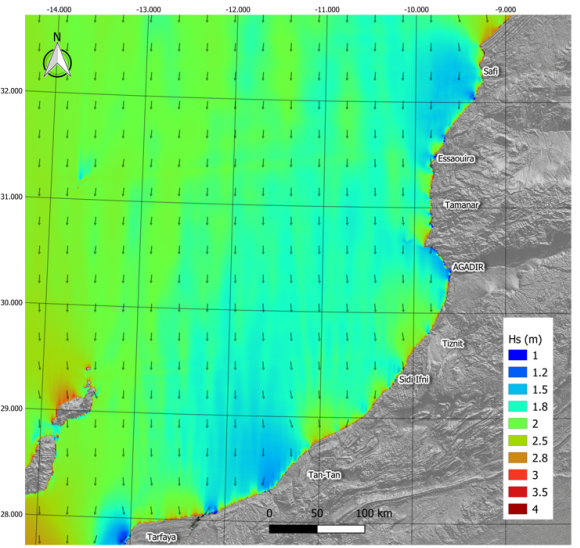

(e)

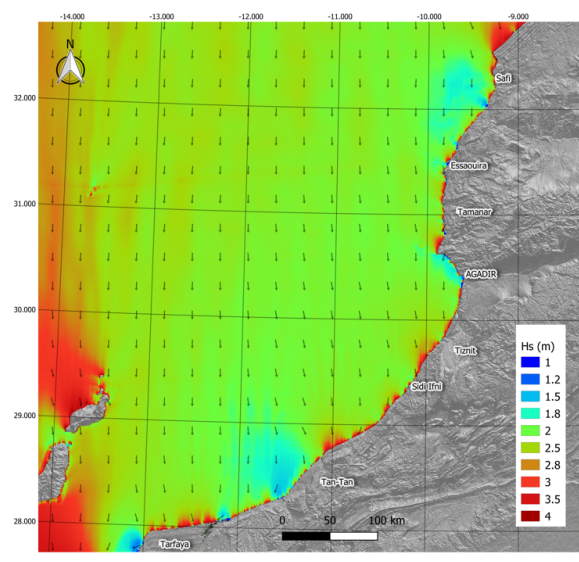

(c)

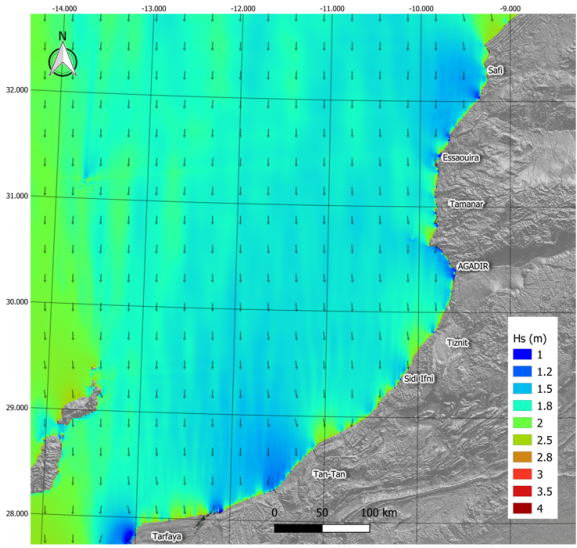

(f)

Figure 6. Cont. 


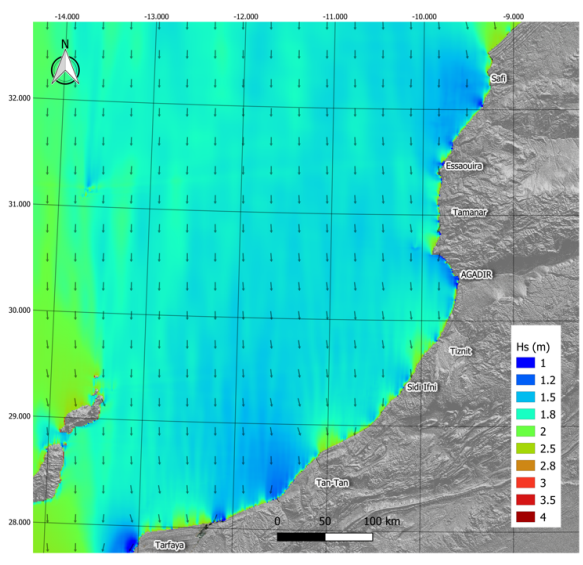

$(\mathrm{g})$

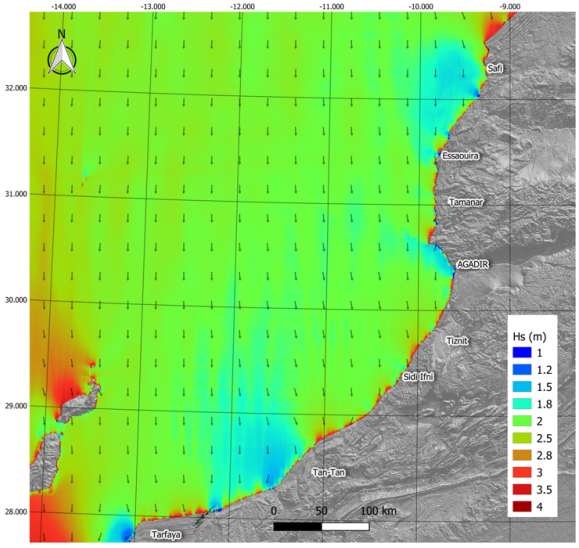

$(\mathbf{j})$

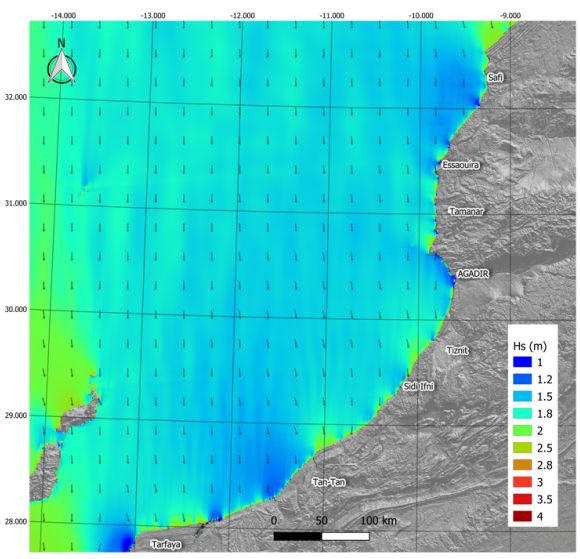

(h)

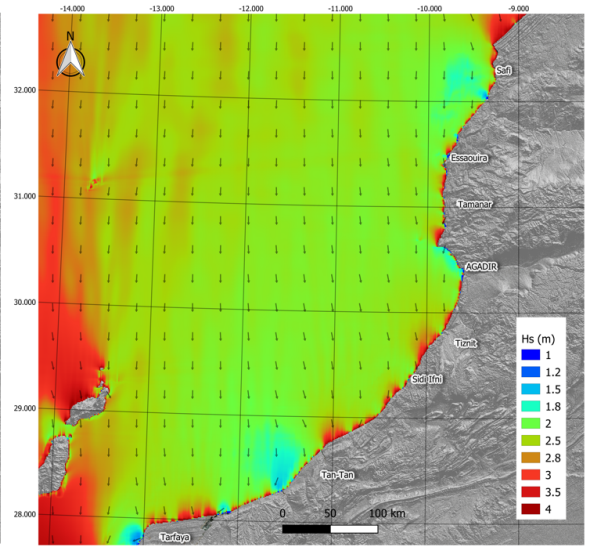

(k)

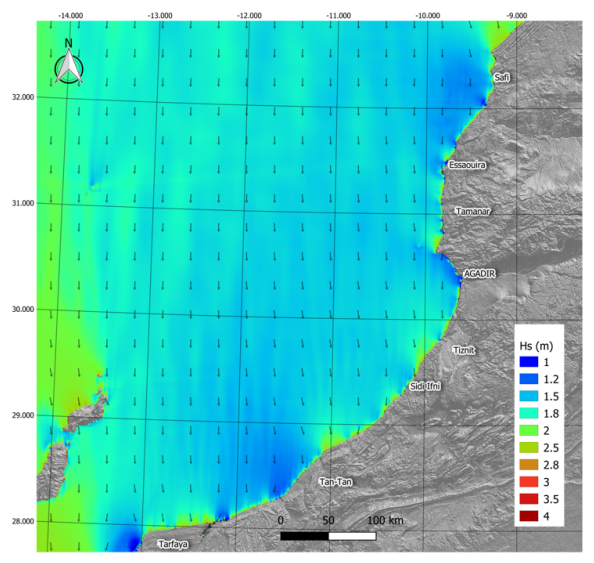

(i)

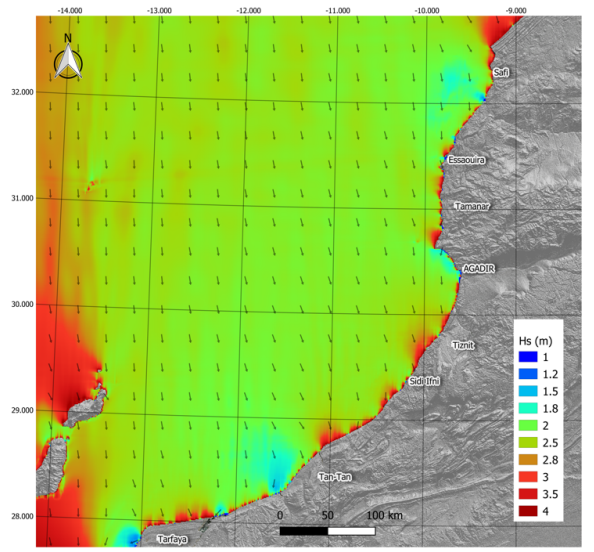

(1)

Figure 6. Monthly 90th percentile mapping of swell from 2003 to 2017. The designation (a1-a3) is the location of zones 1, 2 and 3 inside sub-figure (a: January), those area show the pockets with moderate swell activity. (a) January; (b) February; (c) March; (d) April; (e) May; (f) June; (g) July; (h) August; (i) September; (j) October; (k) November; and (1) December.

The autumn season had values of Hs about $1 \mathrm{~m}$ lower than those of winter. Values during the spring were reduced compared to the fall, while the lowest wave heights were recorded during the summer. Spatially, three sites characterized by moderate activity throughout the year can be distinguished, located at Cape Ghir (Agadir) (Figure 6a1), Tan-Tan (Figure 6a2) and Tarfaya (Figure 6a3)). Following the analysis of Sierra work [14], we detected anomalies of the annual energy values on the points (P13, P17) close to the zones (a1, a2 and a3), caused by the shadow effects of the CAP GHIR in the north and the Canary Islands in the south.

\subsection{GIS Model Product}

The final results of GIS modeling (Figure 7) based on the superposition of wave modeling information with other spatial information layers, shows that the whole area has the potential for favorable wave activity to harbor aquaculture farms.

Spatially, the characteristics of the localized sites make it possible to distinguish between two large zones:

- Zone 1: located between $29.91^{\circ}$ and $30.94^{\circ}$ longitudinal, this zone, which is part of the communes of Tiznit, Chtouka Ait Baha, Inezgane Ait Melloul and also Agadir Idaoutanan, is characterized by the presence of favorable sites in both areas (off-the coast and offshore) with a width that exceeds no longer than $6 \mathrm{~km}$, the total area of the area is around $69 \mathrm{Ha}$ (40 Ha offshore and $29 \mathrm{Ha}$ off-the coast). 
- Zone 2: located towards the south of zone 1 belonging to the communes of Sidi Ifni, Guelmim Tantan and Tarfaya, between $27.89^{\circ}$ and $29.1^{\circ}$ longitudinal, this zone, with the deference of the first one, integrates only one domain (offshore) but this time over a larger area of around 320 ha with a width that can reach $16 \mathrm{~km}$.

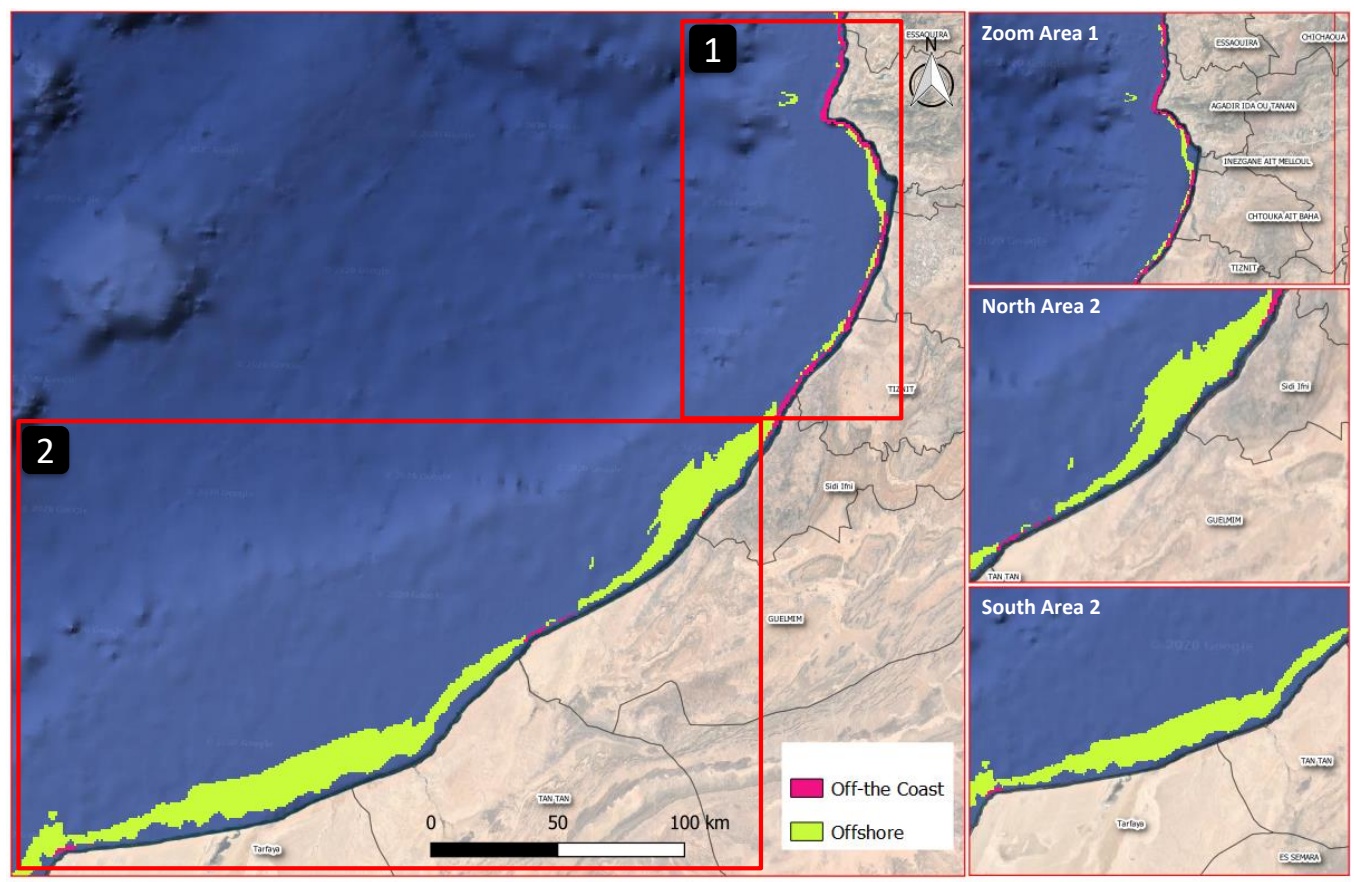

Figure 7. Optimal site summary map (primary site selection).

In general, the width of the continental shelf plays an essential role in the choice of suitable zones, which explains the difference between sites 1 and 2 . For site number 1 , located to the north (near CAP GHIR), the width of the continental shelf is restricted $(4 \mathrm{~km}$ to reach a depth of $60 \mathrm{~m}$ ), characterized by a very steep slope. Unlike Zone 2, located in the south, it has a wider continental shelf ( $17 \mathrm{~km}$ to reach $60 \mathrm{~m}$ deep) with a shallow slope. The average width of the continental shelf is about 40 to $50 \mathrm{~km}[17,37]$

\subsection{Optimal Area and Development Plan}

According to (Figure 8), the development plan (Figure 8b) of the aquaculture sector proposed by the ANDA covers the northern part of our study area (zone 1) (Figure 7), presenting a high percentage of sites located offshore, unlike zone 2 (Figure 7). Given that the results of our diagnosis, which concern the areas located in the (off-the coast-offshore), part (Figure 8a) can form the basis of a possible extension of the development plan proposed by the agency initially limited to the coastal area. 


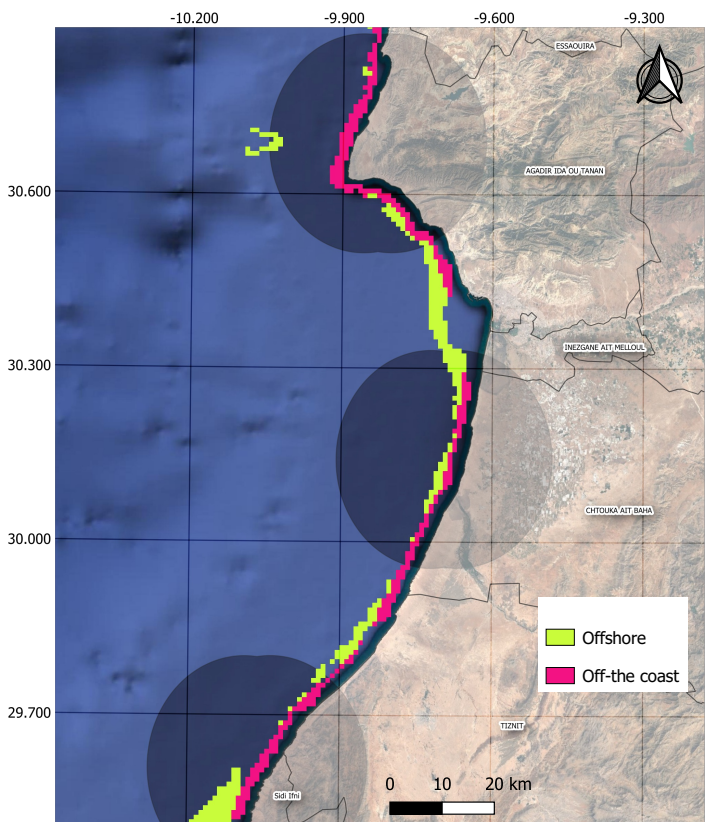

(a)

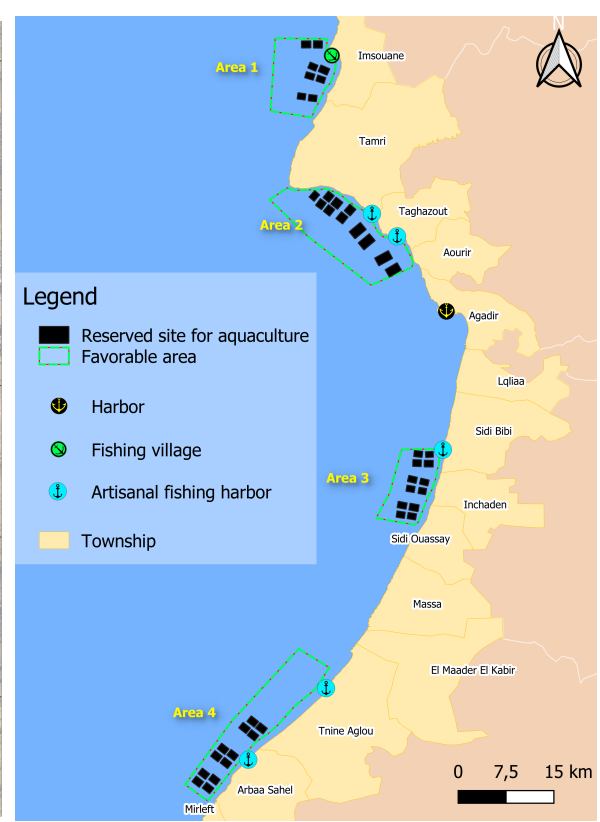

(b)

Figure 8. Comparison between our paper results (a) and the proposed ANDA management plan (b).

\section{Conclusions}

The aims of this paper were to initially delineate primary sites for aquaculture while focusing on the carrying capacity and conventional cages in the face of wave activity. The in-depth study of wave propagation in shallow ocean areas is important to achieve this goal. Due to the SWAN modeling of a third-generation model, the study was carried out by exploiting a significant period of wave data validated by the AVISO altimetry data.

The product obtained led to the delimitation of relevant aquaculture zones after evaluating the potential using modeling under GIS tools. The consistency between the results obtained within the framework of this study and those resulting from a global analysis materialized by a management plan [38] (Figure 8b) confirmed that the selection models remain compliant with the African model (Table 2 in [13]) characterized by the priority of the physical load capacity [39].

On the other hand, the efficiency of the model and the relevance of its results in areas with high swell activity could be considered as an essential tool for decision makers (scientists or investors...) who can position themselves quickly between the attractiveness of the environment and sustainability of the investment. The results highlight the potential of our study area to reach $389 \mathrm{Ha}$ (zone 1 with $69 \mathrm{Ha}$ and Zone 2 with $320 \mathrm{Ha}$ ). While zone 1 is already planned to host aquaculture firms, we suggest investors to go southward (to zone 2).

As researchers, we are often faced with constraints related to the unavailability of information to develop a prospecting strategy, and the current document can serve as a layer of information for a study that aims to target species compatible with the environment, as it can also be used as a road map for non-surveyed areas.

Author Contributions: Conceptualization, M.A.T.; methodology, M.A.T.; software, M.A.T.; validation, A.H., H.R., A.M., A.O. and A.B.; formal analysis, M.A.T.; investigation, M.A.T., A.M. and A.B.; writing-original draft preparation, M.A.T. and A.B.; writing-review and editing, M.A.T., P.B., A.O., H.M. and A.B.; visualization, M.A.T., A.M., P.B., A.O. and B.Z.; supervision, A.H., H.R., A.M. and A.B.; project administration, A.H., H.R. and A.B. All authors have read and agreed to the published version of the manuscript.

Funding: This research received no external funding.

Institutional Review Board Statement: Not applicable. 
Informed Consent Statement: Not applicable.

Data Availability Statement: The data presented in this study are available on request from the corresponding author.

Conflicts of Interest: The authors declare no conflict of interest.

\begin{tabular}{|c|c|}
\hline \\
\hline \multicolumn{2}{|c|}{ Abbreviations } \\
\hline GIS & Geographic Information Systems \\
\hline ANDA & National Aquaculture Development Agency \\
\hline SWAN & Simulating Waves Nearshore \\
\hline WW3 & WAVEWATCH III model \\
\hline AVISO & Archiving, Validation, and Interpolation of Satellite Oceanographic \\
\hline CEM & Environmental Modeling Center \\
\hline MMAB & Modeling and Analysis Branch \\
\hline NCEP & National Environmental Prediction Centers \\
\hline GEBCO & Gridded chart of the European Marine Observation \\
\hline Hs & Significant Wave Height \\
\hline $\mathrm{Tp}$ & Peak Period \\
\hline Dir & Direction \\
\hline UTM & Universal Transverse Mercator \\
\hline CNES & National Center For Space Studies \\
\hline GDAL & Geospatial Data Abstraction Library \\
\hline
\end{tabular}

\section{References}

1. National Aquaculture Development Agency. Guide de l'Investissement en Aquaculture au Maroc Tome 1: Aspects Techniques et Économiques de l'Activité Aquacole; Technical Report; National Aquaculture Development Agency: Battaramulla, Sri Lanka, 2017.

2. Oxford Business Group. Aquaculture in Morocco improves under Halieutis Plan I Morocco 2020 I Oxford Business Group; Oxford Business Group: Dubai, United Arab Emirates, 2020.

3. Brigolin, D.; Lourguioui, H.; Taji, M.A.; Venier, C.; Mangin, A.; Pastres, R. Space allocation for coastal aquaculture in North Africa: Data constraints, industry requirements and conservation issues. Ocean. Coast. Manag. 2015, 116, 89-97. [CrossRef]

4. Boyd, C.E.; Clay, J.W. Shrimp Aquaculture and the Environment. Sci. Am. 1998, 278, 58-65. [CrossRef]

5. Kumar, M., Cripps, S. Aquaculture: Farming Aquatic Animals and Plants, 2nd ed.; Wiley Blackwell: Hoboken, NJ, USA, 2013; 629p. [CrossRef]

6. Soto, D.; Aguilar-Manjarrez, J.; Brugère, C.; Angel, D.; Bailey, C.; Black, K.; Edwards, P.; Costa-Pierce, B.; Chopin, T.; Deudero, S.; et al. Applying an ecosystem-based approach to aquaculture: Principles, scales and some management measures. In Building an Ecosystem Approach to Aquaculture, Proceedings of the FAO/Universitat de les Illes Balears Expert Workshop, Palma de Mallorca, Spain, 7-11 May 2007; FAO Fisheries and Aquaculture Proceedings No. 14; FAO: Quebec City, QC, Canada, 2008 ; pp. 15-35.

7. Gentry, R.R.; Lester, S.E.; Kappel, C.V.; White, C.; Bell, T.W.; Stevens, J.; Gaines, S.D. Offshore aquaculture: Spatial planning principles for sustainable development. Ecol. Evol. 2017, 7, 733-743. [CrossRef] [PubMed]

8. Boyd, C.E.; Schmittou, H.R. Achievement of sustainable aquaculture through environmental management. Aquac. Econ. Manag. 1999, 3, 59-69. [CrossRef]

9. Radiarta, I.N.; Saitoh, S.I.; Miyazono, A. GIS-based multi-criteria evaluation models for identifying suitable sites for Japanese scallop (Mizuhopecten yessoensis) aquaculture in Funka Bay, southwestern Hokkaido, Japan. Aquaculture 2008, 284, 127-135. [CrossRef]

10. Nath, S.S.; Bolte, J.P.; Ross, L.G.; Aguilar-Manjarrez, J. Applications of geographical information systems (GIS) for spatial decision support in aquaculture. Aquac. Eng. 2000, 23, 233-278. [CrossRef]

11. von Thenen, M.; Maar, M.; Hansen, H.S.; Friedland, R.; Schiele, K.S. Applying a combined geospatial and farm scale model to identify suitable locations for mussel farming. Mar. Pollut. Bull. 2020, 156, 111254. [CrossRef]

12. Gimpel, A.; Stelzenmüller, V.; Töpsch, S.; Galparsoro, I.; Gubbins, M.; Miller, D.; Murillas, A.; Murray, A.G.; Pınarbaş1, K.; Roca, G.; et al. A GIS-based tool for an integrated assessment of spatial planning trade-offs with aquaculture. Sci. Total. Environ. 2018, 627, 1644-1655. [CrossRef]

13. Ross, L.; Telfer, T.; Falconer, L.; Soto, D.; Aguilar-Manjarrez, J. Site Selection and Carrying Capacities for Inland and Coastal Aquaculture; FAO: Rome, Italy, 2013; p. 282.

14. Sierra, J.P.; Martín, C.; Mösso, C.; Mestres, M.; Jebbad, R. Wave energy potential along the Atlantic coast of Morocco. Renew. Energy 2016, 96, 20-32. [CrossRef] 
15. Gentry, R.R.; Froehlich, H.E.; Grimm, D.; Kareiva, P.; Parke, M.; Rust, M.; Gaines, S.D.; Halpern, B.S. Mapping the global potential for marine aquaculture. Nat. Ecol. Evol. 2017, 1, 1317-1324. [CrossRef]

16. GEBCO Bathymetric Compilation Group. The GEBCO_2019 Grid-A Continuous Terrain Model of the Global Oceans and Land; British Oceanographic Data Centre: Liverpool, UK, 2019.

17. Benazzouz, A.; Mabchour, H.; Had, K.E.; Zourarah, B.; Mordane, S. Offshore Wind Energy Resource in the Kingdom of Morocco: Assessment of the Seasonal Potential Variability Based on Satellite Data. J. Mar. Sci. Eng. 2021, 9, 31. [CrossRef]

18. Liu, Q.; Babanin, A.V.; Guan, C.; Zieger, S.; Sun, J.; Jia, Y. Calibration and validation of HY-2 altimeter wave height. J. Atmos. Ocean. Technol. 2016, 33, 919-936. [CrossRef]

19. Ardhuin, F.; Rogers, E.; Babanin, A.V.; Filipot, J.F.; Magne, R.; Roland, A.; Van Der Westhuysen, A.; Queffeulou, P.; Lefevre, J.M.; Aouf, L.; et al. Semiempirical dissipation source functions for ocean waves. Part I: Definition, calibration, and validation. J. Phys. Oceanogr. 2010, 40, 1917-1941. [CrossRef]

20. Liu, X.; Huang, W.; Gill, E.W. Estimation of significant wave height from X-band marine radar images based on ensemble empirical mode decomposition. IEEE Geosci. Remote. Sens. Lett. 2017, 14, 1740-1744. [CrossRef]

21. Lader, P.; Jensen, A.; Sveen, J.K.; Fredheim, A.; Enerhaug, B.; Fredriksson, D. Experimental investigation of wave forces on net structures. Appl. Ocean. Res. 2007, 29, 112-127. [CrossRef]

22. Benoit, M.; Marcos, F.; Becq, F. Development of a third generation shallow-water wave model with unstructured spatial meshing In Proceedings of the Coastal Engineering 1996, Orlando, FL, USA, 2-6 September 1996; pp. 465-478.

23. Tolman, H.L. User Manual and System Documentation of WAVEWATCH-III Version 2.22; Technical Note; US Department of Commerce, NOAA, NWS, NCEP: Washington, DC, USA, 2002.

24. Tolman, H.L. User Manual and System Documentation of WAVEWATCH III ${ }^{T M}$ Version 3.14; Technical Note, MMAB Contribution; U. S. Department of Commerce, National Oceanic and Atmospheric Administration, National Weather Service, National Centers for Environmental Prediction: Camp Springs, MD, USA, 2009; Volume 276, p. 220.

25. Booij, N.; Ris, R.C.; Holthuijsen, L.H. A third-generation wave model for coastal regions: 1. Model description and validation. $J$. Geophys. Res. Ocean. 1999, 104, 7649-7666. [CrossRef]

26. Christakos, K.; Furevik, B.R.; Aarnes, O.J.; Breivik, Ø.; Tuomi, L.; Byrkjedal, Ø. The importance of wind forcing in fjord wave modelling. Ocean. Dyn. 2020, 70,57-75. [CrossRef]

27. Ris, R.C.; Holthuijsen, L.H.; Booij, N. Spectral model for waves in the near shore zone. In Proceedings of the 24th International Conference on Coastal Engineering, Kobe, Japan, 23-28 October 1995; Volume 1, pp. 68-78. [CrossRef]

28. Valavanis, V.D. Geographic Information Systems in Oceanography and Fisheries; CRC Press: Boca Raton, FL, USA, 2002.

29. J. Aguilar-Manjarrez D. Soto, J.M.K. The potential of spatial planning tools to support the ecosystem approach to aquaculture. In FAO Fisheries and Aquaculture Proceedings, Proceedings of the FAO/Rome Expert Workshop, Rome, Italy, 19-21 November 2008; Volume $\mathrm{N}^{\mathrm{o}} 17$, Food and Agriculture Organization of the United Nations: Rome, Italy, 2010; p. 176.

30. Aronoff, S. Geographic information systems: A management perspective. Geocarto Int. 1989, 4, 58-58. [CrossRef]

31. Holmer, M. Environmental issues of fish farming in offshore waters: Perspectives, concerns and research needs. Aquac. Environ. Interact. 2010, 1, 57-70. [CrossRef]

32. Lovatelli, A.; Aguilar-Manjarrez, J.; Soto, D. (Eds.) Expanding Mariculture Farther Offshore: Technical, Environmental, Spatial and Governance Challenges. In FAO Fisheries and Aquaculture Proceedings No. 24, FAO Technical Workshop, Orbetello, Italy, 22-25 March 2010; Food and Agriculture Organization of the United Nations: Rome, Italy, 2013. [CrossRef]

33. Kapetsky, J.; Aguilar-Manjarrez, J. Geographic information systems, remote sensing and mapping for the development and management of marine aquaculture. arXiv 2007, arXiv:1011.1669v3.

34. Pérez, O.M.; Telfer, T.C.; Ross, L.G. On the calculation of wave climate for offshore cage culture site selection: A case study in Tenerife (Canary Islands). Aquac. Eng. 2003, 29, 1-21. [CrossRef]

35. Grant, J.; Bacher, C.; Ferreira, J.G.; Groom, S.; Morales, J.; Rodriguez-benito, C.; Saitoh, S.I.; Sathyendranath, S. Remote Sensing Applications in Marine Aquaculture. In Remote Sensing in Fisheries and Aquaculture; IOCCG: Monterey, CA, USA, 2008; pp. 77-88.

36. Pérez, O.M.; Telfer, T.C.; Ross, L.G. Geographical information systems-based models for offshore floating marine fish cage aquaculture site selection in Tenerife, Canary Islands. Aquac. Res. 2005, 36, 946-961. [CrossRef]

37. Mhammdi, N.; Snoussi, M.; Medina, F.; Jaaïdi, E.B. Recent sedimentation in the NW african shelf. Geol. Soc. Mem. 2014, 41, 131-146. [CrossRef]

38. ANDA. Developpement de Projets d'Aquaculture Marine Dans la Region de Souss Massa; Technical Report; The World Bank: Washington, DC, USA, 2014.

39. Ross, L.G.; Mendoza, E.A.; Beveridge, M.C. The application of geographical information systems to site selection for coastal aquaculture: An example based on salmonid cage culture. Aquaculture 1993, 112, 165-178. [CrossRef] 